\title{
Prevention of Mother-to-Child Transmission and Early Real-Time DNA Polymerase Chain Reaction Results Among HIV-Exposed Infants in Bujumbura, Burundi
}

\author{
Joseph Nyandwi, ${ }^{a}$ Sylvestre Bazikamwe, ${ }^{b}$ Désiré Nisubire, ${ }^{c}$ Pontien Ndabashinze, ${ }^{d}$ \\ Mohamed Elsayed Shaker, ${ }^{e}$ Eman Said ${ }^{\mathrm{e}}$ \\ ${ }^{a}$ Hemodialysis Unit, Department of Internal Medicine, University Hospital of Kamenge, Bujumbura, Burundi; ${ }^{b}$ Department of Gynecology and Obstetrics, University \\ Hospital of Kamenge, Bujumbura, Burundi; ${ }^{c}$ Microbiology Unit, Laboratory Department, University Hospital of Kamenge, Bujumbura, Burundi; ${ }^{\mathrm{d}}$ Department of

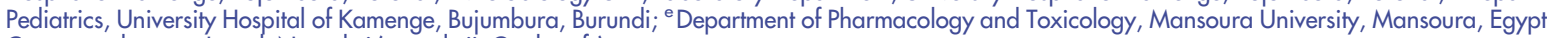 \\ Correspondence to Joseph Nyandwi (nyandwijo@yahoo.fr).
}

\section{ABSTRACT}

Background: Prevention of mother-to-child transmission (PMTCT) programmes aim to both eliminate vertical transmission of HIV and optimise the health and survival of infants born with HIV. Therefore, early infant diagnosis (EID) of HIV infection via DNA polymerase chain reaction (PCR) testing is a key component of PMTCT programming. We assessed the effectiveness of EID and PMTCT interventions at health-care facilities in Bujumbura, Burundi.

Methods: This was a prospective analytical study of infants born to HIV-positive mothers on antiretroviral therapy (ART), who were followed from December 2016 to March 2017 at 3 centres providing PMTCT services in Bujumbura. Babies enrolled in this study received once-daily nevirapine from birth through to 6 weeks of life, after which HIV DNA PCR testing was conducted.

Results: Of $122 \mathrm{HIV}$-exposed infants, 60 were boys and 62 were girls. The mother-to-child transmission rate at 6 weeks of life was $0.9 \%$. Eighty-three $(68 \%)$ of the women had commenced ART before pregnancy and $39(32 \%)$ during pregnancy. The mean CD4 lymphocyte count was $653 \pm 308$ cells/ $\mu$ l. Ninety-two $(75.4 \%)$ of the pregnancies were planned, and $98(80 \%)$ of the births were via spontaneous vaginal delivery. After birth, $111(91.0 \%)$ infants were exclusively breastfed, and 11 (9.0\%) infants received exclusive replacement feeding.

Conclusion: There was a low rate of transmission of HIV from women taking ART to children who were given nevirapine for the first 6 weeks of life. Infants of HIV-positive women can live healthy lives free from HIV infection if their mothers participate in PMTCT programmes.

\section{INTRODUCTION}

$\mathbf{H}$ IV/AIDS remains a disease of great public health importance, and vertical transmission of HIV from mother to child - continues to be a common route of transmission, accounting for the vast majority of new infections in children. ${ }^{1}$ In 2012, about 330,000 children under 15 years of age worldwide were infected with HIV, according to estimates by the Joint United Nations Programme on HIV and AIDS (UNAIDS), with more than $90 \%$ of paediatric HIV infections occurring in sub-Saharan Africa. ${ }^{1}$ Most of these infections occurred during pregnancy, delivery, or breastfeeding, thereby making the prevention of mother-to-child transmission (PMTCT) an important public health strategy for reducing HIV transmission. ${ }^{2}$

PMTCT programmes provide antiretroviral therapy (ART) to HIV-positive pregnant women to prevent their infants from acquiring the virus. Effective PMTCT programmes require women and their infants to have access to and make use of a cascade of interventions, including antenatal services and HIV testing during pregnancy, ART for pregnant women living with HIV, safe childbirth and appropriate infant feeding practices, and infant HIV testing and other postnatal health-care services. ${ }^{3}$ In the absence of such interventions, the risk of mother-to-child transmission (MTCT) of HIV is $15 \%$ to $45 \%$. However, ART 
and other effective PMTCT interventions can reduce this risk to below $5 \%{ }^{4}$

Early infant diagnosis (EID) permits the detection of HIV infection in exposed children from 4 to 6 weeks of age via a polymerase chain reaction (PCR) assay. In infants, HIV infection may progress to full-blown AIDS within the first few months of life. The advent of EID has brought about considerable survival benefits for HIV-infected infants who receive early ART. ${ }^{5}$ EID also permits the assessment of PMTCT programme effectiveness.

The Burundi PMTCT programme was implemented in 2000. The goal was to achieve virtual elimination of HIV infection in infants and young children. In 2011, the UNAIDS Global Plan was launched to reduce the number of new HIV infections acquired via MTCT by $90 \%$ by 2015.6 The World Health Organization (WHO) identified 22 priority countries, with the top 10 -including Burundi - accounting for $75 \%$ of the global PMTCT services need. It was estimated that the effective scale-up of interventions in these countries would prevent over 250,000 new infections annually. The 2010 Burundian Demographic and Health Survey reported a decrease of HIV prevalence in the general population from about $3 \%$ in 2007 to $1.4 \%$ in 2010 (1\% in men and $1.7 \%$ in women). ${ }^{7}$ New HIV infections, acquired via MTCT, among children under 5 years of age accounted for $25 \%$ of all new infections during the same period. In 2016, Burundi had 84,000 people living with HIV, among whom were 4,300 pregnant women who received ART for PMTCT. WHO reporting estimated that fewer than 500 children were newly infected with HIV due to MTCT. $^{8}$ Despite sustained PMTCT efforts, infants of HIV-positive women are at risk of becoming infected after birth. One of the major ways of reducing HIV transmission is by ensuring the consistent implementation of EID. The WHO recommends DNA realtime PCR (RT-PCR) HIV testing at 4 to 6 weeks of life for infants of HIV-positive mothers, and commencement of ART for HIV-positive children below 24 months of age. ${ }^{1,2,9}$

This study examined EID with DNA RT-PCR at 3 health facilities in Bujumbura, Burundi, with the aim of assessing the effectiveness of PMTCT interventions towards reducing vertical transmission of HIV.

\section{METHODS}

\section{Study Design and Setting}

This was a prospective analytical study of pregnant women enrolled in the Burundi PMTCT programme, implemented according to national guidelines. The study was conducted from December 2016 to March 2017 at 3 health facilities providing HIV screening, antenatal care, and PMTCT services in Bujumbura: the Buyenzi Community Medical Centre (CMC); the Society for Women Against AIDS in Africa (SWAA), Burundi; and the Burundian National Association of Support for People Living with HIV and AIDS Patients (ANSS).
The Buyenzi CMC is a public urban antenatal care clinic and was the first centre to implement PMTCT in Burundi in 2000 .

The Burundi branch of the SWAA International was built in 1992 thanks to the initiative of a group of women wishing to fight the taboo and stigma attached to HIV/AIDS. It is a nonprofit organisation dedicated to HIV prevention and client support among women, children, families, and communities by providing medical and psychosocial support. At the end of June 2015, the SWAA sites in Burundi were monitoring 5,238 people, including 3,530 taking ART.

Founded in 1993, the Burundian ANSS was the first civil society organisation in Burundi to provide HIV prevention, care, and treatment services aimed at improving the well-being of people living with and affected by HIV. In 2016, 506 women were registered with the ANSS PMTCT programme.

\section{Study Population}

This study focused on pregnant women living with HIV-1 infection and taking ART. Eligible women were those who were enrolled in PMTCT programmes at the 3 participating health-care facilities and expected to give birth within 6 weeks before the end of the study period. Babies delivered to enrolled women were included. Exclusion criteria among infants included being a second twin or a third triplet because of the reported lower MTCT risk among second twins and third triplets. ${ }^{10} \mathrm{CD} 4$ cell counts were done during antenatal care. HIV-exposed infants received $2 \mathrm{mg} / \mathrm{kg}$ of once-daily nevirapine from birth for 6 weeks and were thereafter screened for HIV-1 by DNA RT-PCR.

\section{Blood Analysis}

Blood analysis was carried out in the Department of Virology at the National Reference Laboratory of the National Institute of Public Health in Bujumbura. Whole blood samples $(6 \mathrm{ml})$ drawn from the expectant mothers were collected in ethylenediaminetetraacetic acid (EDTA) tubes at the laboratories of each PMTCT service and directly transported to the National Institute of Public Health, where plasma was separated from the whole blood after centrifugation at $40,000 \mathrm{~g}$ for 10 minutes. The plasma was then stored in $1.5 \mathrm{ml}$ aliquots at $-80^{\circ} \mathrm{C}$. CD4 T-cells were counted using the BD FACSCount System (Becton Dickinson, San Jose, CA, USA). At 6 weeks of life, all children born to enrolled mothers underwent qualitative DNA RT-PCR HIV testing. Dried blood spots from capillary samples were prepared on Whatman blotting papers and stored at room temperature until being used for DNA RT-PCR analysis with the Abbott RealTime HIV-1 Qualitative kit (Abbott Laboratories, Abbott Park, IL, USA). According to the manufacturer, the DNA RTPCR assay has a specificity of $100 \%$ and a sensitivity of at least 2,500 copies/ml using the dry blood spot procedure. 


\section{Data Collection and Management}

Data collection was conducted by a team of trained and supervised nurse data collectors. The principal investigator monitored data collection, and another senior member of the study team frequently conducted random checks to ensure data quality. Error and data consistency checks were conducted during analysis. Data were extracted from structured national data collection tools and entered into Microsoft Excel spreadsheets designed for data entry. The national tools from which the data for analysis were drawn included the PCR request and result forms as well as the EID register, containing information about the baseline characteristics of HIV-exposed babies, type of ART received by the mother, frequency of antenatal care follow-up, mode of delivery, mother's ART start date, infant feeding method, and outcome of the DNA RT-PCR test.

\section{Data Analysis}

Data entered into the Microsoft Excel spreadsheet were cleaned and checked for consistency. The cleaned data were exported to Statistical Package for the Social Sciences (SPSS) for Windows, version 12.0 (SPSS Inc., Chicago, IL, USA), for data management and further statistical analysis. Frequency counts were performed to assess the completeness of all variables. The DNA RT-PCR result was the primary outcome variable and was determined for HIV-exposed infants at 6 weeks of life.

\section{Ethical Approval}

This study was approved by the Comité d'Éthique et de Recherche en Santé Humaine (Committee of Ethics and Research in Human Health) of the Faculty of Medicine of the University of Burundi in accordance with the code of ethics for biomedical research involving human subjects (reference no. FM/CE/04/2016). Women were included in the study after they received a detailed explanation of the aim of the study and gave their written voluntary consent, when they were able to do so, and verbal consent if they were unable to read or write. The study used routinely collected, aggregated programme data at the 3 health-care facilities, and participant confidentiality was ensured, as personal identifiers - including names and identification numbers were not recorded with the collected data.

\section{RESULTS}

The study population was composed of 122 pregnant women and 122 babies. The mean age of the women was $31 \pm 6.6$ years (range, 17 to 44 years); over half $(n=62$, $50.8 \%$ ) of the women were aged between 30 and 39 years. Ninety-two $(75.4 \%)$ of the pregnancies were planned, and $30(24.6 \%)$ were unplanned. Eighty-three $(68.0 \%)$ women commenced ART before pregnancy, and 39 (32.0\%) began ART during pregnancy. The mean CD4 cell count for the women was $653 \pm 308$ cells/ $\mu$ l, and $79(64.7 \%)$ had $\geq 500 \mathrm{CD} 4$ cells $/ \mu \mathrm{l}$. Only $1(0.8 \%)$ mother gave birth at home, and the rest $(n=121,99.2 \%)$ delivered at health facilities (Table 1$)$. Most $(n=98,80.3 \%)$ participants delivered via spontaneous vaginal delivery, with 24 (19.7\%) delivering through caesarean section (Table 2).

All 122 babies were born at term ( $\geq 37$ weeks of gestation); $60(49.2 \%)$ of the newborns were boys, and $62(50.8 \%)$ were girls. Most $(n=111,91.0 \%)$ of the infants received exclusive breastfeeding during the first 6 weeks of life; the other $11(9.0 \%)$ children received exclusive replacement feeding. At 6 weeks of age, 121 (99.2\%) infants tested negative for HIV by DNA RT-PCR, and $1(0.8 \%)$ child tested positive (Table 2).

TABLE 1. Baseline Characteristics of Women Enrolled in the Study ( $\mathrm{N}=122)$

\begin{tabular}{lc}
\hline Characteristics & $\mathbf{n}(\%)$ \\
\hline Age (years) & $2(1.6)$ \\
$<19$ & $29(23.8)$ \\
$20-24$ & $18(14.8)$ \\
$25-29$ & $31(25.4)$ \\
$30-34$ & $31(25.4)$ \\
$35-39$ & $11(9.0)$ \\
$\geq 40$ & \\
Prepregnancy plan & $92(75.4)$ \\
Planned pregnancy & $30(34.6)$ \\
Unplanned pregnancy & \\
Place of delivery & $121(99.1)$ \\
Health-care facility & $1(0.9)$ \\
Home & $83(68.0)$ \\
Timing of mother's antiretroviral therapy commencement \\
Before pregnancy & $39(32.0)$ \\
During pregnancy & $2(1.6)$ \\
CD4 T-lymphocyte count (/HI) during antenatal care \\
$\leq 200$ & $24(19.7)$ \\
$201-349$ & $79(64.7)$ \\
$350-499$ & \\
$\geq 500$ & \\
\end{tabular}




\begin{tabular}{lc}
\hline TABLE 2. Selected Characteristics of HIV-Exposed \\
Infants (N=122) \\
\hline Characteristics & $\mathbf{n}(\%)$ \\
\hline Sex & $60(49.2)$ \\
Male & $62(50.8)$ \\
Female & \\
Mode of delivery & $94(77.0)$ \\
Vaginal & $28(23.0)$ \\
Caesarean section & \\
Preterm delivery (<37 weeks of gestation) & $122(100)$ \\
No & $0(0)$ \\
Yes & $111(91.0)$ \\
Feeding option adopted by mother & $11(9.0)$ \\
Exclusive breastfeeding & \\
Exclusive replacement feeding & $1(0.8)$ \\
HIV DNA RT-PCR result at 6 weeks of age & $121(99.2)$ \\
Positive & \\
Negative & \\
\hline Abbreviation: RT-PCR, real-time polymerase chain reaction (assay).
\end{tabular}

\section{DISCUSSION}

Nearly all ( $\mathrm{n}=121,99.2 \%)$ of the enrolled infants tested negative by HIV DNA RT-PCR at 6 weeks of age. The 1 child who had a positive test was born at home and immediately transferred to the PMTCT centre, where nevirapine prophylaxis was initiated; however, the treatment did not continue at home. The MTCT rate of $0.8 \%$ is consistent with findings from a previous retrospective study conducted at Buyenzi CMC. In that study, Bindariye et al screened 774 children for PMTCT from January 2008 to December 2010, finding an MTCT rate of $1.4 \% .{ }^{11}$ In another prospective follow-up study of 843 HIV-infected mothers from 2009 to 2011 , the MTCT rate was $1.2 \%{ }^{12}$ This is also comparable to findings of $0.0 \%$ for Option B+ studies conducted in Burkina Faso and Ethiopia. ${ }^{13,14}$ Option B+ is a treatment approach that recommends immediate lifelong ART for all pregnant women living with HIV, regardless of CD4 count, and daily nevirapine or zidovudine for HIV-exposed infants from birth until 4 to 6 weeks of age, regardless of infant feeding method. ${ }^{15}$

Burundi, like several African countries, opted for Option B+ in 2014, which is why all expectant mothers enrolled in this study were already on the standard ART regimen, according to national guidelines. ${ }^{15}$ This may have contributed to the decline in the rate of HIV MTCT in Burundi. Eighty-three $(68 \%)$ women were on lifelong ART before the pregnancy investigated in this study, and 39 (32\%) women started treatment after testing positive for HIV during the applicable pregnancy. The mean CD4 count was $653 \pm 308$ cells $/ \mu \mathrm{l}$, and only $2(1.64 \%)$ women had CD 4 counts $<200$ cells $/ \mu$ l. These levels could be due to antiretroviral drugs reducing maternal viral load and thereby reducing the risk of HIV transmission from mother to child by creating good conditions for the pregnancy. ART provides other antenatal and postnatal benefits; for example, in a Nigerian study, the rate of HIV transmission among infants of HIV-positive mothers was higher in babies whose mothers did not receive ART during pregnancy $(28.6 \%)$ compared with those whose mothers commenced ART during pregnancy $(5.4 \%)$, and it was lowest among those whose mothers commenced ART before pregnancy (3.4\%). ${ }^{16}$ Our results are promising in the light of the further rollout of PMTCT interventions in sub-Saharan Africa, especially considering the most recent "test and treat", or "treat all", approach that recommends immediate initiation of treatment for all HIV-infected individuals, including pregnant women. ${ }^{17}$ However, high MTCT rates have still been reported relatively recently in Africa, specifically $6.3 \%$ at a tertiary hospital in Ado-Ekiti, Nigeria; $6.5 \%$ among public health-care facilities in Lusaka, Zambia; and $2.8 \%$ among public health-care facilities in South Africa. ${ }^{16,18,19}$

In our study, $98(80.3 \%)$ women underwent vaginal deliveries and $24(20 \%)$ underwent caesarean sections. This was in line with national guidelines that recommend against systematic caesarean deliveries for HIV-infected pregnant women. The frequency of caesarean section was largely determined by maternal and infant complications and not by maternal HIV status, and our caesarean section rate was similar to rates reported by other African studies. ${ }^{16,20,21}$

In our study, all babies were born at term. In a Nigerian study, the authors reported undesirable obstetric and neonatal outcomes in $48.3 \%$ of HIV-positive women compared to $30.3 \%$ of HIV-negative women. Preterm delivery and miscarriage were among the independent factors associated with HIV. ${ }^{22}$ In a Spanish study on the effect of highly active antiretroviral therapy (HAART) on spontaneous and iatrogenic preterm delivery, Lopez et $\mathrm{al}^{23}$ found that the incidence of prematurity was $19.7 \%$ in HIV-positive women and $8.5 \%$ in the control group. Prematurity secondary to treatment was significantly associated with the use of HAART during the second half of pregnancy. The incidence of spontaneous preterm birth was also higher among HIV-positive women not on HAART. ${ }^{23}$

WHO recommends antiretroviral prophylaxis for HIVexposed neonates immediately after birth for 6 to 12 weeks. ${ }^{9}$ Nevirapine prophylaxis is recommended for 6 weeks for breastfeeding infants and for 4 to 6 weeks for infants 
who are not breastfeeding. ${ }^{24}$ In this study, all infants received nevirapine prophylaxis from birth to 6 weeks of life, regardless of whether they received exclusive breastfeeding $(\mathrm{n}=111,91.0 \%)$ or exclusive replacement feeding $(\mathrm{n}=11,9.0 \%)$. Exposed-infant antiretroviral prophylaxis serves as pre- and post-exposure prophylaxis and is especially protective against HIV acquisition via breastfeeding. ${ }^{24-26} \mathrm{~A}$ recent meta-analysis showed that HIV-exposed infants who do not receive antiretroviral prophylaxis at or after birth are more than 7 times more likely to become HIV-infected than infants who receive antiretroviral prophylaxis. ${ }^{27}$ Several studies have underscored the importance of infant antiretroviral prophylaxis in preventing MTCT of HIV. ${ }^{24,25}$

Despite all of these encouraging results, many studies have identified different maternal, obstetric, and child-level factors that determine antenatal, perinatal, and postnatal MTCT of HIV. Olana et al noted various predictive factors associated with positivity of DNA RT-PCR HIV testing at 6 to 8 weeks of age among children born to HIV-positive mothers: home delivery, maternal CD4 count $<100$ cells/ $\mu$ l during pregnancy, absence of PMTCT interventions for the mother, absence of prenatal consultations, and non-enrolment in an HIV-management programme during pregnancy. ${ }^{14}$ Mixed feeding, which has had reported rates of $5 \%$ in Botswana and Cameroon, has also been identified as an important risk factor for MTCT of HIV and infant deaths. ${ }^{28,29}$ Lack of participation in mother-to-mother support programmes, low partner involvement, poor ART adherence, positive syphilis test results, maternal malnutrition, and unplanned pregnancy have also been associated with MTCT of HIV. ${ }^{30}$

\section{Limitations}

Our study's limitations include the short study period. A longer study period could have allowed for the inclusion of more participants, leading to more consistent results. The study was carried out at 3 centres with broad experience in managing PMTCT interventions. The centres are located in Bujumbura, where accessibility to heath facilities is high compared with the rest of the country. Our results, therefore, are not generalisable to the entire country. Additionally, this study focused only on EID of HIV at 6 weeks of age. Future studies should evaluate the effectiveness of PMTCT programmes until HIV-exposed infants reach 18 months of age.

\section{CONCLUSION}

This study highlighted the low rate of MTCT of HIV when HIV-positive pregnant women receive ART and the infants born to these women receive nevirapine for the first 6 weeks of life. Infants born to HIV-positive women can live healthy lives free from HIV infection if their mothers participate in PMTCT programmes. To identify infants with HIV and monitor those at risk of infection, HIV testing and counselling programmes focused on PMTCT interventions should be scaled up in antenatal, labour and delivery, and postnatal settings. Also, institutional and community-based comprehensive health education programmes that emphasise the importance of skilled birth attendance, postpartum care, and PMTCT interventions are essential. This calls for the Ministry of Public Health and other concerned partners to work towards improving the PMTCT programme by making DNA RT-PCR testing available and accessible to all families of exposed infants for early HIV diagnosis.

\section{REFERENCES}

1. Dube Q, Dow A, Chirambo C, et al; CHIDEV study team. Implementing early infant diagnosis of HIV infection at the primary care level: experiences and challenges in Malawi. Bull World Health Organ. 2012;90(9):699-704. CrossRef. Medline

2. World Health Organization (WHO). Report of the WHO Technical Reference Group, Paediatric HIV/ART Care Guideline Group Meeting. Geneva: WHO; 2008. http://www.who.int/hiv/pub/paediatric/WHO_Paediatric_ART_guideline_rev_ mreport_2008.pdf. Accessed 23 September 2018.

3. Padian NS, McCoy SI, Karim SS, et al. HIV prevention transformed: the new prevention research agenda. Lancet. $2011 ; 378(9787)$ :269-278. CrossRef. Medline

4. World Health Organization (WHO). Mother-to-child transmission of HIV. WHO Website. http://www.who.int/hiv/topics/mtct/en/. Accessed 23 September 2018.

5. Violari A, Cotton MF, Gibb DM, et al; CHER Study Team. Early antiretroviral therapy and mortality among HIV-infected infants. N Engl J Med. 2008;359(21):22332244. CrossRef. Medline

6. Joint United Nations Programme on HIV/AIDS (UNAIDS) Count Down To Zero: Global Plan Towards the Elimination of New HIV Infections Among Children by 2015 and Keeping Their Mothers Alive. Geneva: UNAIDS; 2011 . http://files. unaids.org/en/media/unaids/contentassets/documents/unaidspublication/ 2011/20110609_JC2137_Global-Plan-Elimination-HIV-Children_en.pdf. Accessed 28 September 2018.

7. Institut de Statistiques et d'Études Économiques (ISTEEBU), Ministère de la Santé Publique et de la Lutte contre le SIDA (MSPLS), ICF International. Enquête Démographique et de Santé du Burundi 2010. Bujumbura, Burundi: ISTEEBU, MSPLS, and ICF International; 2012. https://dhsprogram.com/pubs/pdf/FR253/ FR253.pdf. Accessed 23 September 2018.

8. World Health Organization (WHO). Burundi. HIV Country Profile: 2016. Geneva: WHO; 2017. http://www.who.int/hiv/data/Country_profile_Burundi.pdf. Accessed 23 September 2018.

9. World Health Organization (WHO). Antiretroviral Drugs for Treating Pregnant Women and Preventing HIV Infection in Infants: Recommendations for a Public Health Approach. Geneva: WHO; 2010. http://www.who.int/hiv/pub/mtct/ antiretroviral2010/en/. Accessed 24 September 2018.

10. Mandelbrot L, Msellati P, Meda N, et al; ANRS 049 Ditrame Study Group. 15 Month follow up of African children following vaginal cleansing with benzalkonium chloride of their HIV infected mothers during late pregnancy and delivery. Sex Transm Infect. 2002;78(4):267-270. CrossRef. Medline

11. Bindariye M. HIV prevalence among children born to HIV-positive mothers followed in prenatal consultation for prevention mother to child transmission at Buyenzi Communal Medical Centre: retrospective study of 774 children screened January 2008-December 2010 [abstract O.2.2.001]. Trop Med Int Health. 2013; 18(suppl 1):82-83. CrossRef. Medline

12. Leroy H, Chapplain J-M, Nindagiye E, Ntizahurye S, Biziragusenyuka J, Arvieux C. Achieving elimination of mother to child HIV transmission in Burundi from the experience of an antenatal care centre in Bujumbura: prospective follow-up of $843 \mathrm{HIV}$ infected mothers [abstract MOPE 1 10]. Poster presented at: 7th IAS Conference on HIV Pathogenesis, Treatment and Prevention; 30 June to 3 July 2013; Kuala Lumpur, Malaysia. http://pag.ias2013.org/EPosterHandler.axd?aid=1 187. Accessed 24 September 2018 
13. Sagna T, Bisseye C, Compaore TR, Kagone TS, Diigma FW et al. Prevention of mother-to-child HIV-1 transmission in Burkina Faso: evaluation of vertical transmission by PCR, molecular characterization of subtypes and determination of antiretroviral drugs resistance. Glob Health Action 2015, 8: 26065. CrossRef. Medline

14. Olana T, Bacha T, Worku W, Tadesse BT. Early infant diagnosis of HIV infection using DNA-PCR at a referral center: an 8 years retrospective analysis. AIDS Res Ther. 2016;13(1):29. CrossRef. Medline

15. Ministère de la Santé Publique et de la Lutte contre le SIDA (MSPLS), Conseil National de Lutte contre le SIDA Secretariat Executif Permanent. Politique Nationale de Prévention de la Transmission du VIH de la Mère à l'Enfant. Bujumbura, Burundi: MSPLS; 2010. http://www.grandir.sidaction.org/wpcontent/uploads/2015/03/Politique-Nationale-PTME_Burundi_2010.pdf. Accessed 24 September 2018.

16. Oluwayemi IO, Olatunya SO, Ogundare EO. PCR Results and PMTCT Treatment Outcomes among HIV-Exposed Infants in a Tertiary Hospital in Nigeria, 20102014. Int J MCH AIDS. 2015;3(2):168-173. Medline

17. World Health Organization (WHO). Consolidated Guidelines on the Use of Antiretroviral Drugs for Treating and Preventing HIV Infection: Recommendations for a Public Health Approach, 2nd ed. Geneva: WHO; 2016. http://www. who.int/ hiv/pub/arv/arv-2016/en/. Accessed 24 September 2018.

18. Stringer JS, Sinkala M, Maclean CC, et al. Effectiveness of a city-wide program to prevent mother-to-child HIV transmission in Lusaka, Zambia. AIDS. 2005; 19(12):1309-1315. CrossRef. Medline

19. Barron P, Pillay $Y$, Doherty T, et al. Eliminating mother-to-child HIV transmission in South Africa. Bull World Health Organ. 2013;91(1):70-74. CrossRef. Medline

20. Cissé CAT, Inzale MA, Wade NF, Niang MM, Diallo D, Ndiaye Seye N. Dépistage et prise en charge de l'infection à VIH chez la femme enceinte à Dakar. Med Sante Trop. 2018;28(2):186-192. CrossRef. Medline

21. Derebe G, Biadgilign S, Trivelli M, et al. Determinant and outcome of early diagnosis of HIV infection among HIV-exposed infants in southwest Ethiopia. BMC Res Notes. 2014;7(1):309. CrossRef. Medline

22. Ezechi OC, Gab-Okafor CV, Oladele DA, et al. Pregnancy, obstetric and neonata outcomes in HIV positive Nigerian women. Afr J Reprod Health. 2013;17(3):160168. Medline

23. Lopez $M$, Figueras $F$, Hernandez $S$, et al. Association of HIV infection with spontaneous and iatrogenic preterm delivery: effect of HAART. AIDS. 2012;26(1):37-43. CrossRef. Medline

24. Hurst SA, Appelgren KE, Kourtis AP. Prevention of mother-to-child transmission of HIV type 1: the role of neonatal and infant prophylaxis. Expert Rev Anti Infect Ther 2015;13(2):169-181. CrossRef. Medline
25. Kourtis AP, Bulterys M. Mother-to-child transmission of HIV: pathogenesis, mechanisms and pathways. Clin Perinatol. 2010;37(4):721-737, vii. CrossRef. Medline

26. Mandelbrot $L$, Burgard $M$, Teglas $J P$, et al. Frequent detection of HIV-1 in the gastric aspirates of neonates born to HIV-infected mothers. AIDS. 1999;13(15):21432149. Medline

27. Kassa GM. Mother-to-child transmission of HIV infection and its associated factors in Ethiopia: a systematic review and meta-analysis. BMC Infect Dis. 2018;18(1):216. CrossRef. Medline

28. Thior I, Lockman S, Smeaton LM, et al; Mashi Study Team. Breastfeeding plus infant zidovudine prophylaxis for 6 months vs formula feeding plus infant zidovudine for 1 month to reduce mother-to-child HIV transmission in Botswana: a randomized trial: the Mashi Study. JAMA. 2006;296(7):794-805. CrossRef. Medline

29. Koye DN, Zeleke BM. Mother-to-child transmission of HIV and its predictors among HIV-exposed infants at a PMTCT clinic in northwest Ethiopia. BMC Public Health. 2013;13:398. CrossRef. Medline

30. Beyene GA, Dadi LS, Mogas SB. Determinants of HIV infection among children born to mothers on prevention of mother to child transmission program of HIV in Addis Ababa, Ethiopia: a case control study. BMC Infect Dis. 2018;18(1):327. CrossRef. Medline

\section{Peer Reviewed}

Competing Interests: None declared.

Received: 9 Jan 2018; Accepted: 5 Oct 2018

Cite this article as: Nyandwi J, Bazikamwe S, Nisubire D, Ndabashinze P, Elsayed Shaker M, Said E. Prevention of Mother-to-Child Transmission and Early Real-Time DNA Polymerase Chain Reaction Results Among HIV-Exposed Infants in Bujumbura, Burundi. East African Health Res J. 2018;2(2):112-117. https://doi.org/10.24248/ EAHRJ-D-18-00003

(C) Nyandwi et al. This is an open-access article distributed under the terms of the Creative Commons Attribution License, which permits unrestricted use, distribution, and reproduction in any medium, provided the original author and source are properly cited. To view a copy of the license, visit http://creativecommons.org/licenses/by/ 4.0/. When linking to this article, please use the following permanent link: DOI: https://doi.org/10.24248/EAHRJ-D-18-00003 